\title{
Interações Discursivas nas Manifestações de Habilidades Cognitivas em um Clube de Ciências
}

\section{Discursive Interactions in Cognitive Skills in a Science Club}

\author{
Antonia Ediele de Freitas Coelho ${ }^{a}$; João Manoel da Silva Malheirob \\ a Instituto de Educação Matemática e Científica, Universidade Federal do Pará, Belém, Brasil \\ antonia.coelho@castanhal.ufpa.br \\ b Faculdade de Pedagogia, Universidade Federal do Pará, Castanhal, Brasil - joaomalheiro@ufpa.br
}

Palavras-chave: Interações discursivas. Abordagem comunicativa. Habilidades cognitivas. Clube de ciências.

\section{Keywords:}

Discursive interactions. Communicative approach. Cognitive skills. Science club.
Resumo: Este estudo analisa as Interações Discursivas evidenciadas em um Clube de Ciências de uma Universidade Federal e sua influência para a manifestação de Habilidades Cognitivas nos alunos, durante a etapa de aproximação com a realidade de uma Sequência de Ensino Investigativo. Caracterizamos esta investigação como qualitativa e o local analisado é considerado um ambiente não formal de educação, onde desenvolvem-se atividades práticas investigativas por meio da experimentação, possuindo direcionamento para as Ciências e Matemáticas. Participaram da pesquisa 22 alunos do $5^{\circ}$ e $6^{\circ}$ anos, sendo selecionados 5 estudantes, acompanhados por um professor monitor. A atividade analisada foi intitulada "Problema do Copo" e explorou conteúdos relacionados ao ar e seu lugar no espaço. Evidenciamos que as Interações Discursivas identificadas auxiliaram para a manifestação de Habilidades Cognitivas nos alunos. Identificamos predominância de abordagem comunicativa interativo/dialógica e níveis de Habilidades Cognitivas alternando entre Baixa (N2, N3) e Alta Ordem de Cognição (N4, N5).

\begin{abstract}
This study analyzes the Discursive Interactions evidenced in a Science Club of a Federal University and its influence to the manifestation of Cognitive Skills in the students, during the stage of Approach with the reality of a Sequence of Investigative Teaching. We characterize this research as qualitative and the place analyzed is considered a non-formal educational environment, where practical investigative activities are developed by means of experimentation, with a focus on Science and Mathematics. 22 students from the 5th and 6th years participated in the research, being selected 5 students, accompanied by a teacher monitor. The activity analyzed was titled "Problem of the Glass" and explored contents related to the air and its place in the space. We showed that the identified Discourse Interactions aided in the manifestation of Cognitive Abilities in students. We identified predominance of interactive / dialogic communicative approach and levels of Cognitive Skills alternating between Lower (N2, N3) and High Order of Cognition (N4, N5).
\end{abstract}




\section{Introdução}

Desvendar as curiosidades a respeito da constituição, composição e organização das coisas que nos cercam é algo que faz parte da expectativa de grande parte dos sujeitos, principalmente ao se considerar àqueles que se deparam em fase escolar, os quais procuram encontrar na escola respostas às suas indagações que não foram totalmente supridas em outros ambientes de convívio social, conforme nos reporta Carvalho et al. (2009).

Considerando isso, Zoller e Pushkin (2007) acrescentam que existem vários pesquisadores que investigam de que forma o convívio social e cultural influencia no desenvolvimento e manifestações da aprendizagem, tentando identificar como e por que o cérebro aprende e quais as intervenções que o convívio em sala de aula, promovem nessa construção do conhecimento.

Assim, Bakhtin (2011) esclarece que o ato de contar sua história, narrar fatos que constituem a vida, se apresentam de forma valiosa ao ponto de conectar cada um à sua experiência, a experiência do outro, do antepassado, amalgamando o pessoal e o coletivo. Esse autor considera que as Interações Discursivas decorrentes do contato e diálogo com o outro, constitui-se a partir de um processo eminentemente social, no qual as vozes se interrelacionam, convivem, questionam e se fazem entender (ou não).

Em suas obras, Bakhtin $(2006 ; 2011)$ propõe que a alternância de discursos por meio de enunciados que se constroem em vivências, é direcionada ao interlocutor limitando-se a seu horizonte social. Portanto, a aprendizagem de conceitos se dá a partir do entendimento de que vivemos em um mundo repleto de palavras alheias, onde a comunicação verbal, da interação com o outro, só ocorre a partir do momento em que se considera que o "eu" existe na medida em que se relaciona com o "você".

Mortimer e Scott (2002) veem na abordagem comunicativa possibilidades de Interações para o desenvolvimento de aprendizagens, que podem ocorrer a partir da maneira como professores interagem com os alunos, e permitem que eles se inter-relacionem.

Sobre isso, Silva (2015) investigou de que maneira as Interações Discursivas entre alunos e professores monitores, participantes de um curso de férias, influenciaram no desenvolvimento do conhecimento científico em uma equipe de estudantes do ensino fundamental. $\mathrm{O}$ autor descreve características que evidenciam como o processo de ensino e aprendizagem se constituiu durante as Interações demonstradas, além de utilizar as teorias de Bakhtin para apresentar a variabilidade de abordagens comunicativas que puderam ser destacadas no processo de ensinar e aprender ciências, que o referido curso possibilita para o surgimento da aprendizagem. 
Ao investigar as Interações que ocorrem em um clube de ciências, Nery (2018) descreveu a respeito das Interações Discursivas e o tipo de abordagem comunicativa que surgiram por meio dos padrões de interações desenvolvidos pelos professores monitores. De acordo com o autor, foi possível perceber que esses padrões de Interações foram essenciais para o surgimento de indícios de aprendizagem, pois como a metodologia adotada no clube, que é baseada no ensino investigativo, não oferece procedimentos automáticos para a resolução de problemas de maneira imediata, permitiu aos alunos analisarem situações novas, testarem hipóteses, realizarem questionamentos, tudo isso organizado em grupo e com auxílio dos professores monitores.

Essas possibilidades podem ser organizadas por meio da constituição de discursos considerados dialógicos ou de autoridade que se diferenciam, sobretudo, pela forma como o professor considera o que o aluno tem a dizer em sua completude ou destacando apenas o conteúdo científico de seus discursos, respectivamente.

Dessa maneira, as formas de intervenções que o professor sugere durante as aulas compreendem outros aspectos relevantes, que determinam nossa compreensão sobre as Interações Discursivas e as oportunidades de desenvolvimento de Habilidades Cognitivas.

Quando consideramos os processos cognitivos, Zoller e Pushkin (2007) entendem o pensamento como o primeiro passo para a construção de ideias, crenças e ações, consistindo na habilidade de desenvolver responsabilidade e controle sobre a mente, auxiliando na capacidade de discernimento.

O conhecimento, no que lhe concerne, também apresenta uma hierarquia em sua constituição, que são definidas conforme o sujeito vai se tornando capaz de reconhecer aspectos relevantes para resolver problemas e de ligá-los a princípios específicos, que são representados pela eficiência em expor essa capacidade (ZOLLER; PUSHKIN, 2007).

Com base nesses elementos, são evidenciadas as Habilidades Cognitivas que, por seu lado, se sobrepõe às categorias de pensamento e conhecimento, não com o intuito de substituílos, mas de complementá-los em suas incongruências.

Nesse aspecto, propomos com esta investigação analisar de que maneira as Interações Discursivas podem influenciar na manifestação de Habilidades Cognitivas no Clube de Ciências Prof. Dr. Cristovam W. P. Diniz”, da Universidade Federal do Pará - campus Castanhal. Para isso, identificamos as principais características das Interações Discursivas propostas nas pesquisas de Bakhtin (2006; 2011). Verificamos as possibilidades da abordagem comunicativa em Mortimer e Scott (2002) e, por fim, conferimos em Zoller (2002; 2007) as possibilidades da manifestação de Habilidades Cognitivas, destacando a relevância do pensamento e do conhecimento nesse processo. 


\section{O discurso na perspectiva de Bakhtin}

Em suas obras, Bakhtin (2006) considera que ser é comunicar-se dialogicamente e, por isso, o mundo que nos rodeia está povoado de vozes de diferentes sujeitos, que se tornam palavras através dos enunciados. O autor assume o enunciado como objeto de estudo da linguagem, sendo encoberto de significações e cultura. Dessa forma, se considera que o aspecto discursivo é, ao mesmo tempo, social e histórico, presumindo-se ainda suas relações internas e externas, com destaque na interação verbal, organizacional, em seu contexto e intertexto.

Para Bakhtin (2006), a concepção da linguagem se constrói a partir do princípio dialógico, sendo este a abertura constitutiva de todo o discurso. Silva (2015), considera que o dialogismo em Bakhtin, é vetor condicionante da significação do discurso, "o fator ligante da linguagem e a existência cultural, concebendo-se tanto na interação verbal, enunciador e o enunciatário, quanto no interior do discurso, o dialogismo da interdiscursividade" (p. 11).

Defendemos a ideia de que a palavra é neutra em relação a quaisquer funções ideológicas específicas, pois ela pode preencher cada uma dessas funções, seja ela estética, científica, moral ou religiosa. Ressaltamos ainda que "existe uma parte importante da comunicação ideológica que não pode ser vinculada a uma esfera ideológica particular: tratase da comunicação na vida cotidiana" (BAKHTIN, 2006, p. 35, grifo do autor).

Consideramos esse aspecto, consideravelmente rico e importante, já que ao mesmo tempo em que está vinculada a processos de produção, está ainda ligada às esferas das diversas ideologias especializadas e formatizadas. A utilização da língua, ao se tratar da ação humana de comunicação, organiza-se em forma de enunciados concretos e únicos, sejam eles escritos ou orais. Esses aspectos, refletem condicionantes específicos com fim em cada campo de atuação, por meio de expressões que compõem conteúdo temático e estilo verbal, que podem ser identificados a partir de Interações cotidianas.

De acordo com Bakhtin (2006), a verdadeira constituição da língua não é composta por um sistema de formas linguísticas, ou somente pela enunciação monológica solitária, ou ainda pelo ato psicofisiológico de sua formação, mas sim, "pelo fenômeno social da interação verbal, realizada através da enunciação ou das enunciações” (p. 125, grifos do autor). A realidade fundamental da língua é a Interação verbal e, nesse aspecto, o diálogo é entendido com uma das constituições mais importantes da Interação verbal, embora compreenda apenas uma das formas de suas possíveis manifestações.

Nesse sentido, podemos compreender o termo "diálogo" dentro de um sentido amplo de seu significado, ou seja, não envolve tão-somente a comunicação em voz alta, entre pessoas próximas, que se comunicam face-a-face, mas todo tipo de comunicação, de qualquer 
forma que seja. Para explicar essa afirmação, Bakhtin (2006) utiliza o exemplo do livro, como sendo um relevante elemento da comunicação verbal, pois ele é feito para ser estudado, apreendido e criticado dentro de um discurso interior, sem se considerar as reações impressas e institucionalizadas que podem ser encontradas dentro das diferentes esferas que envolvem esse tipo de comunicação.

Dessa maneira, se defende a relevância da escrita nesse processo, descrevendo-a como uma forma de transcrição codificada das vozes, capaz de delinear os sentidos do diálogo ontológico. Para Bakhtin (2006) a escrita é prerrogativa de um percurso capaz de traduzir a voz humana, uma vez que é portadora dos sentidos da existência. Do mesmo modo, consideramos que a palavra é utilizável como um signo interior, e pode funcionar como signo sem expressões externas ao indivíduo.

O discurso escrito, é defendido como sendo “[...] de certa maneira parte integrante de uma discussão ideológica em grande escala: ele responde a alguma coisa, refuta, confirma, antecipa as respostas e objeções potenciais, procura apoio, etc.” (BAKHTIN, 2006, p. 126).

Em relação a isso, destacamos que os procedimentos que incluem a compreensão de fenômenos ideológicos não podem ocorrer sem a participação do discurso interior, já que todos os signos não-verbais, se constituem no discurso e, por isso, não conseguem ser nem totalmente isolados, nem inteiramente opostas a ele.

É necessário ressaltar ainda que essa afirmação não implica acreditar que a palavra é capaz de suplantar qualquer outro signo ideológico, pois nenhum outro pode ser substituído por palavras e permanecer com seus significados intrínsecos. Nesse sentido, exemplifica-se que é praticamente impossível exprimir por palavras um ato religioso, uma composição musical ou uma representação pictórica, pois, para Bakhtin (2006), não existe sequer uma expressão verbal consistente para substituir o significado de um simples gesto humano.

Apesar disso, consideramos que mesmo que esses signos não sejam expressos unicamente por palavras, cada um deles se sustenta e é conduzido por elas, haja vista que, "a palavra está presente em todos os atos de compreensão e em todos os atos de interpretação" (BAKHTIN, 2006, p. 36). Ressaltamos que os signos compreendem todas as formas de manifestações ideológicas, podendo ser representado não apenas como parte da realidade, mas também reflete e refrata uma outra e, por isso, todo signo está sujeito a critérios de avaliações ideológicas.

Nesse contexto, os gêneros que compõem o discurso são enunciados que se constroem enquanto estruturas firmes, constituídas em diversificados espaços que compreendem as ações humanas. Segundo Bakhtin (2011), o gênero do discurso deve ser considerado como uma forma da língua, e também como um tipo do enunciado. 
Assim sendo, o gênero inclui determinada expressão peculiar, inerente ao enunciado. Enquanto que a palavra ganha certa expressão típica, ou seja, "os gêneros correspondem a situações típicas da comunicação discursiva, a temas típicos, por conseguinte, a alguns contatos típicos dos significados das palavras com a realidade concreta em circunstâncias típicas" (BAKHTIN, 2011, p. 293, grifo do autor).

Isso justifica como algumas expressões peculiares, características de determinada cultura, em algumas situações parecem se sobrepor ao uso das palavras. Assim, os gêneros do discurso instituem infinitas variedades que se diferenciam por sua heterogeneidade, embora ordenem os conhecimentos sociais de variadas maneiras, de acordo com a intenção e propósito de cada locutor.

Considerando a heterogeneidade dos gêneros do discurso, Bakhtin (2011), ressalta a importância de distinguir tais gêneros entre primários e secundários. Sendo que, de maneira generalizada, os primários aludem a ocasiões comunicativas espontâneas, cotidianas, mais informais e menos elaboradas, carregado de particularidades, em que se afasta de sua relação com a realidade e com os enunciados de quem se dialoga.

Enquanto que os gêneros secundários, comumente são mediados pela escrita, e surgem em situações comunicativas mais elaboradas, complexas, de diálogo cultural como, por exemplo, em romances, teses, no teatro, etc. É importante destacar que apesar de suas particularidades, a essência dos gêneros primários e secundários é a mesma, o que significa acrescentar que são compostos por fenômenos de mesma natureza, que são os enunciados verbais, mesmo que sejam diferenciados pela ocasião onde são propagados.

Apesar disso, ressaltamos que a natureza do enunciado deve ser descoberta e definida, pois a utilização dos gêneros é acentuada pelo contexto discursivo, a posição social, cultural e interpessoal entre os participantes que compõem tal comunicação. Assim, acreditamos que "toda a minha vida, então, não é senão a orientação no mundo das palavras alheias, desde assimilá-las, no processo de aquisição da fala, e até apropriar-me de todos os tesouros da cultura" (BAKHTIN, 2006, p. 347).

Somamos a isso a compreensão de que a consciência humana é um fato sócio ideológico, pois os signos só conseguem existir e se materializar por meio da solidificação da comunicação social. Por sua vez, a palavra é assimilada pela função de cada signo e representa o modo mais puro e evidente de relação social, haja vista que a palavra se designa como efeito vivo das forças sociais.

Complementando essa ideia evidenciamos que a fala, o enunciado, o discurso são afirmações sociais que compõem a natureza social do indivíduo, não unicamente individual e, por essa razão, está indissoluvelmente conectada às condições da comunicação que, por outro lado, estão sempre conexas às estruturas sociais. 
Logo, percebemos que investigar a respeito das Interações Discursivas é notoriamente essencial, em razão de que, permiti-nos analisar as relações sociais que envolvem as comunicações entre os sujeitos e sua natureza constitutiva. Afinal, se a fala está intrinsicamente relacionada às transformações linguísticas, ela não se vincula unicamente aos indivíduos, mas permite a eles o confronto de valores sociais, pensamentos e ideias, incluindo nesse processo a escrita, como forma de exposição de pensamentos.

\section{A abordagem comunicativa em Mortimer e Scott}

A abordagem comunicativa, segundo a proposta de Mortimer e Scott (2002), possui um conceito que é central na estrutura analítica "fornecendo a perspectiva sobre como o professor trabalha as intenções e o conteúdo do ensino por meio das diferentes intervenções pedagógicas que resultam em diferentes padrões de interação” (p. 287, grifo do autor).

Considerando o processo de ensino e aprendizagem, as Interações Discursivas que emergem na relação professor-aluno e aluno-aluno, compreendem vários contextos e conteúdos e se propõem a resolução de determinada atividade, com o intuito de "[...] concluir uma dada tensão-cognitiva" (BAKHTIN, 2011, p. 177).

A estrutura analítica definida por Mortimer e Scott (2002), se baseia em cinco aspectos que estão inter-relacionados, tem como foco o papel do professor e são agrupadas em termos de focos do ensino, abordagem e ações, definidos da seguinte maneira:

$\checkmark$ Focos de ensino: 1. Intenções do professor 2. Conteúdo;

$\checkmark$ Abordagem comunicativa: 3. Abordagem comunicativa;

$\checkmark$ Ações: 4. Padrões de interação; 5. Intervenções do professor ${ }^{1}$.

Para analisar esses aspectos das Interações Discursivas, Mortimer e Scott (2002), organizaram alguns aspectos que se compõem em consonância com as ideias de Bakhtin (2006; 2011) e expressam características da linguagem social, sendo delimitadas da seguinte maneira:

- Descrição: se referem a um sistema, objeto ou fenômeno, em termos de seus constituintes ou dos deslocamentos espaço-temporais desses constituintes;

- Explicação: importa algum modelo teórico ou mecanismo para se referir a um fenômeno ou sistema específico;

- Generalização: elabora descrições ou explicações que são independentes de um contexto específico.

\footnotetext{
1 Apesar de considerarmos essenciais todos os pontos que compreendem a ferramenta analítica proposta por Motimer e Scott (2002), para fins de investigação e análise dessa pesquisa optamos por utilizá-la a partir da Abordagem Comunicativa (item 3 da descrição), pois estes tópicos foram os que mais se destacaram durante a análise dos discursos selecionados.
} 
Para além disso, são identificadas quatro classes de abordagem comunicativa, determinadas pelo aspecto do discurso entre professor e alunos ou mesmo entre os próprios alunos, dependendo do tipo de discussão realizada, denominadas de: discurso dialógico ou de autoridade e discurso interativo ou não interativo (MORTIMER; SCOTT, 2002).

Nesse cenário, estabelecem-se duas distintas maneiras de interação entre professor e alunos. Na dimensão em que se constitui o discurso dialógico ou de autoridade, no primeiro extremo o professor considera o que os estudantes têm a dizer, levando em conta os diferentes pontos de vistas, permitindo uma inter-animação de vozes, já que se admite o contato com mais de uma voz, caracterizando o discurso dialógico (AMARAL et al., 2003).

No segundo extremo, apenas o conteúdo científico dito pelo aluno é levado em consideração, apenas uma voz é ouvida (a científica), não havendo a inter-animação de ideias, evidenciando o discurso de autoridade (MORTIMER; SCOTT, 2002).

Assim outro aspecto da abordagem comunicativa se relaciona a interatividade, distinguindo o discurso entre interativo, que emerge com a participação de mais de um indivíduo e, não-interativo quando apenas uma pessoa participa (MORTIMER; SCOTT, 2002). Esses aspectos da abordagem comunicativa estabelecem quatro classes que podem ser sintetizadas da seguinte maneira:

a) Interativo/Dialógico: $\mathrm{O}$ professor e os estudantes exploram ideias, formulam perguntas autênticas, oferecem e consideram diferentes pontos de vista;

b) Não-Interativo/Dialógico: O professor reconsidera, em sua fala, variados pontos de vista, destacando similaridades e diferenças entre os fatos apresentados e suas relevâncias;

c) Interativo de autoridade: O professor geralmente conduz os estudantes por meio de uma sequência de perguntas, com objetivo de chegar a um ponto de vista específico;

d) Não-interativo de autoridade: O professor apresenta um ponto de vista específico e não considera os pontos que possam ter sido destacados pelos estudantes em qualquer momento da discussão.

Nessa perspectiva, os autores estabelecem um padrão de interação que surge a partir do momento em que professores e alunos alteram turnos de fala. Constitui-se assim uma tríade mais frequente, com base na Iniciação do professor, seguido da Resposta do aluno e concluída com a Avaliação do professor (I-R-A).

No entanto, consideramos ainda a possibilidade de estabelecimento de outros padrões, isso origina "cadeias de turnos não triádicas do tipo I-R-P-R-P... ou I-R-F-R-F... onde $\mathbf{P}$ significa uma ação discursiva de permitir o prosseguimento da fala do aluno e $\mathbf{F}$ um feedback" (MORTIMER; SCOTT, 2002, p. 288, grifo do autor). Dessa maneira, são consideradas as seguintes possibilidades para essas relações, conforme vemos na figura 1: 


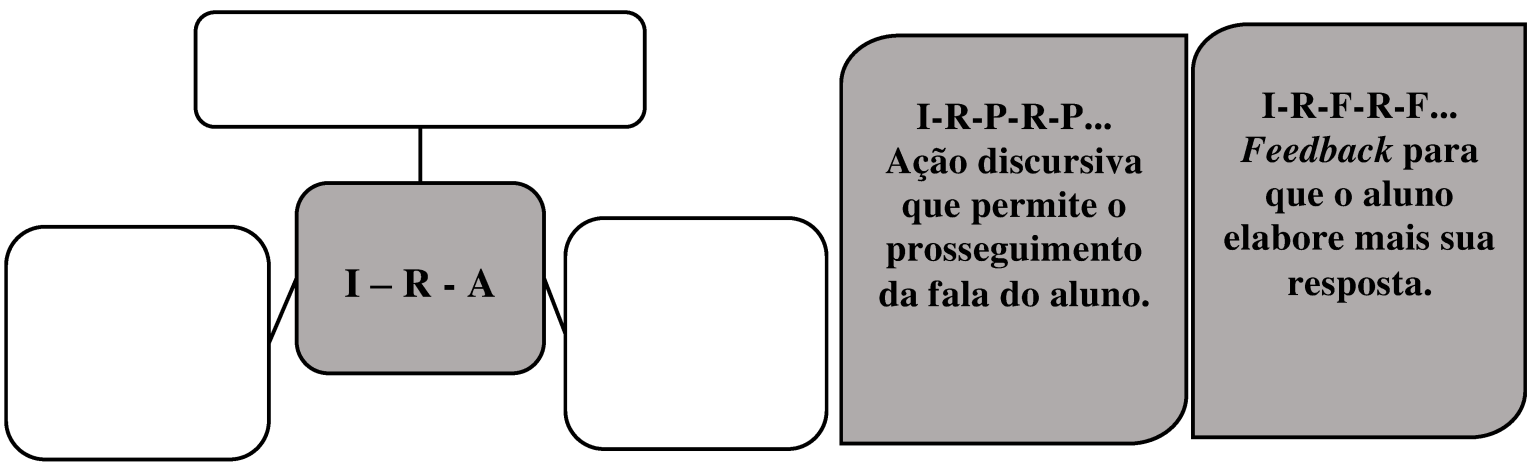

Figura 1: Padrões de Interações

Fonte: Adaptado de Mortimer e Scott (2002) e Silva (2015)

As intervenções do professor também são organizadas e distribuídas segundo a sequência desenvolvida no ensino, procurando direcionar suas ações as finalidades traçadas em seu planejamento. A esse respeito, Mortimer e Scott (2002), elaboram uma síntese de como isso pode ser percebido:

$\checkmark$ Dando forma aos significados: Explora o conhecimento prévio/trabalha novas significações;

$\checkmark$ Selecionando significados: Na sua fala: considera/ignora a resposta do aluno;

$\checkmark$ Marcando significados chaves: Repete um enunciado; Utiliza I-R-A para confirmar uma ideia;

$\checkmark$ Compartilhando significados: Disponibiliza os significados dos alunos; repete enunciados, compartilha resultados;

$\checkmark$ Checando o entendimento: Verificar que significados os estudantes estão atribuindo em situações específicas/explicar melhor; verifica se há consenso;

$\checkmark$ Revendo o progresso: Recapitula significados/síntese dos resultados, revê progressos.

A partir disso, esses tópicos procuram sintetizar as formas de intervenções pedagógicas dos professores, na qual seis intervenções tornaram-se possíveis de serem evidenciadas.

\section{As Habilidades Cognitivas}

Definimos a aprendizagem ou aprendizado como o conjunto de comportamentos que adquirimos ao longo de nossa vida, considerando que o homem interage com o ambiente desde o nascimento, através das mais variadas atitudes. Em relação a isso, a Guerra (2011) esclarece que alguém aprende alguma coisa quando "adquire atitudes, comportamentos, competências para se adaptar a novas situações, para resolver problemas" (p. 3). 
Nesse sentido, a inteligência humana pode ser compreendida como um guarda-chuva, por meio do qual podemos entender a natureza da cognição, considerando sua capacidade de adaptação a diferentes estímulos e situações, conforme sugere Sternberg (2010). Para este autor, a inteligência humana ou sua capacidade de aprender, compreende a estrutura que organiza a cognição e, por isso, acrescentamos que a cognição se "articula para nos proporcionar uma maneira funcionalmente unificada de entendermos e de nos adaptarmos ao ambiente" (STERNBERG, 2010, p. 8).

Da mesma maneira, destacamos ainda que a obtenção de comportamentos novos, ou seja, a construção da aprendizagem, garante ao sujeito recursos para que ele consiga sobreviver, sendo responsável também por diversas capacidades mentais, como a emoção, a memória, atenção, percepção, etc. (GUERRA, 2011).

Segundo Sternberg (2010) a cognição consegue se inter-relacionar com a competência de resolver problemas, isto é, a aptidão para discernir entre as variadas informações que são adquiridas em unidades, nas quais se incentive as capacidades superiores e a memória, desenvolvendo o que nomeamos de conhecimento.

Considerando isso, Maturana (2001) compreende a cognição humana como nossa capacidade de fazer ou operar os comandos de nossas ações ou comportamentos, além de destacar as relações que se firmam durante o processo de: administrar afirmações, responder ou tentar responder questionamentos sobre o que conhecemos ou queremos aprimorar.

Dessa maneira, o conhecimento se constitui como qualquer domínio particular construído na cognição por meio de distinções, operações, comportamentos, pensamentos ou reflexões, incorporado às ações ou condutas adequadas a cada situação "avaliadas de acordo com nosso próprio critério de aceitabilidade para o que constitui uma ação adequada nele" (MATURANA, 2001, p. 127).

Na concepção de Lipman (1995), podemos compreender que a cognição humana é responsável pela habilidade de pensamento e, por meio disso, é capaz de gerar a capacidade de elaborar soluções a problemas propostos, bem como a competência de poder criticá-los, sendo esses alguns dos resultados do conhecimento. Dessa forma, o indivíduo torna-se apto ao que o autor nomeia de "julgamento", ou seja, habilita-se para formar opiniões, avaliações, conclusões, incluindo igualmente, a tomada de decisão e aprendizagem de novos conceitos.

Além disso, de acordo com as ideias de Lipman (1995), acrescentamos que todos os sujeitos possuem habilidades básicas desde o nascimento e, que são essenciais para desenvolver a capacidade de pensar. Por conta disso, todos pensam, mesmo que, nem todos consigam racionar "bem". Segundo o autor, para que se alcance o que ele considera como "pensar bem", é preciso estimular a partir da educação escolar, as Habilidades Cognitivas de 
Pensamento, destacando que estas habilidades costumam ocorrer de forma interligada ao contexto ou situação problema a que são direcionadas.

Acrescentamos que existe um termo genérico entre as associações e as disjunções, que são as relações que os unem ou separam. Podemos destacar que o significado das complexidades existentes na organização do pensamento, se define com base nas afinidades que eles podem possuir ou não com outros agrupamentos, pois "cada relacionamento, quando descoberto ou inventado, é um significado, e grandes ordens ou sistemas de relacionamentos constituem grandes corpos de significados" (LIPMAN, 1995, p. 33).

A partir disso, Lipman (1995) evidencia que pensar é o processo de conceber os vínculos que existem na realidade e conseguir reproduzir ou traduzir em nossas consciências, o que nos possibilita deduzir para os significados ou os sentidos que podem estar implícitos ou explícitos no fato percebido.

Segundo Zoller e Pushkin (2007), o pensamento compreende a capacidade de os alunos solucionarem problemas dentro e fora do ambiente escolar, além de envolver a habilidade de tomar responsabilidade e controle sobre nossa mente. Ademais, pensar também define a decisão do que fazer (ou não), em determinadas situações, tendo como consequência a tomada de responsabilidade pelas ações selecionadas.

Sternberg (2010), compreende a reflexão com um processo inerente ao conhecimento, para o autor "o conhecimento sem reflexão é inútil, e a reflexão sem conhecimento é vazia" (p. 7), ou seja, é necessário que se equilibre a relação existente entre a aprendizagem de conteúdos e a reflexão existente em cada um deles. Consideramos ainda que é necessário desacreditar em ideias que tentam "definir que a inteligência tanto pode ser inteira, ou quase totalmente, determinada pela genética, ou então, que é completa ou quase inteiramente determinada pelo ambiente", já que "em nosso desenvolvimento, natureza e criação operam de maneira conjunta" (STERNBERG, 2010, p. 13).

Nesse aspecto, para Zoller et al., (2002), o pensamento e o conhecimento estão intimamente ligados, sendo um responsável pela (co)existência do outro, podendo assim, em algumas situações serem considerados sinônimos, dentro das perspectivas adotadas por Lipman (1995) e Zoller et al., (2002).

Assim, pensamento, conhecimento e cognição se tornam diretamente ligados e do mesmo modo, as Habilidades Cognitivas são manifestadas a partir da forma como os estudantes vão tornando-se capazes de lidar com ocasiões que compreendem problemas, fazendo com que a aprendizagem se torne um fato que necessita de perguntas, discussões, memórias, hipóteses e resultados (MIRI et al., 2007; ZOLLER; PUSHIKIN, 2007).

Determinadas Habilidades Cognitivas são apresentadas e classificadas por Zoller et al., (2002), Zoller e Pushkin (2007). Essas habilidades foram organizadas como: Algorítmicas 
$(A L G)$, Habilidades Cognitivas de Baixa Ordem (LOCS - Lower Order Cognitive Skills), e Habilidades Cognitivas de Alta Ordem (HOCS - Higher Order Cognitive Skills).

A Habilidade Algorítmica pode tanto evidenciar uma categoria única, quanto como uma categoria inferior à de Habilidades Cognitivas de Baixa Ordem (LOCS), caracterizandose por conceber exteriorização de pensamentos, nas quais os estudantes são conduzidos a evidenciar ou utilizar conhecimentos algorítmicos memorizados para responder "perfeitamente" exercícios simples ou que requerem uma resposta direta, ou, "uma resposta correta a uma questão bem definida" (ZOLLER; PUSHKIN, 2007, p. 154, tradução nossa).

Segundo a concepção dos autores, as Habilidades Cognitivas de Baixa Ordem são caracterizadas com o intuito de evidenciar equações, definições formais, algorítmicos, que se sintetizam em saber, identificar, lembrar ou definir conceitos, conteúdos ou ainda fórmulas memorizadas que são utilizados somente em situações problemas cotidianos, isto é, por meio de exercícios diretivos e sem problematizar o que está sendo estudado.

Ao alcançar as Habilidades Cognitivas de Alta Ordem, evidencia-se que é a ocasião em que o indivíduo imediatamente compreende as informações proeminentes do problema, suas possibilidades de variação e, consequentemente, surgem as hipóteses iniciais como oportunidade de soluções mais plausíveis aos objetivos indicados. A resolução de problemas nesse aspecto, não diz respeito a exercícios, pois abrange a constituição do pensamento crítico, da tomada de decisão, pois os problemas não são de conhecimento dos estudantes e precisam de conhecimentos suplementares para seu desenvolvimento. Com base nisso, Zoller e Pushkin (2007) definem níveis de Habilidades que são construídos com base nestas categorias. No quadro 1, a seguir, propomos exemplificar essa relação:

Quadro 1: Níveis de Habilidades Cognitivas

\begin{tabular}{|c|c|}
\hline Nível & Categoria de resposta ALG \\
\hline N1 & $\begin{array}{ll}\checkmark & \text { Não reconhece a situação problema; } \\
\checkmark & \text { Limita-se a expor um dado relembrado; } \\
\checkmark & \text { Retêm-se a aplicação de fórmulas ou conceitos. }\end{array}$ \\
\hline Nível & Categoria de resposta LOCS \\
\hline $\mathbf{N} 2$ & $\begin{array}{ll}\checkmark & \text { Reconhece a situação problemática e identifica o que deve ser buscado; } \\
\checkmark & \text { Não identifica variáveis; } \\
\checkmark & \text { Não estabelece processos de controle para a seleção das informações; } \\
\checkmark & \text { Não justifica as respostas de acordo com os conceitos exigidos. }\end{array}$ \\
\hline $\mathbf{N 3}$ & $\begin{array}{l}\checkmark \text { Explica a resolução do problema utilizando conceitos já conhecidos ou relembrados (resoluções } \\
\text { não fundamentadas, por tentativa) e quando necessário representa o problema com fórmulas ou } \\
\text { equações; } \\
\checkmark \text { Identifica e estabelece processos de controle para a seleção das informações; } \\
\checkmark \text { Identifica as variáveis, podendo não compreender seus significados conceituais. }\end{array}$ \\
\hline Nível & Categoria de resposta HOCS \\
\hline $\mathbf{N 4}$ & $\begin{array}{l}\checkmark \text { Seleciona as informações relevantes; } \\
\checkmark \text { Analisa ou avalia as variáveis ou relações causais entre os elementos do problema; } \\
\checkmark \text { Sugere as possíveis soluções do problema ou relações causais entre os elementos do problema. } \\
\checkmark \text { Exibe capacidade de elaboração de hipóteses. }\end{array}$ \\
\hline N5 & $\checkmark$ Aborda ou generaliza o problema em outros contextos ou condições iniciais. \\
\hline
\end{tabular}


Fonte: Zoller e Pushkin (2007); Coelho (2016)

Percebemos que estes níveis se tornam atingíveis dependendo da forma como os estudantes são direcionados pelo professor em busca da resolução de um problema. Suart (2008) considera que as soluções elaboradas pelos estudantes possuem relação direta com os questionamentos do professor, pois, verificou-se que o nível cognitivo de respostas dadas pelos alunos é determinado pelo tipo de pergunta que é estabelecida pelo educador, ressaltando a função do docente enquanto mediador dos conhecimentos que serão constituídos pelos alunos.

\section{Metodologia da investigação}

Para alcançar os objetivos desta investigação assumimos uma proposta de abordagem qualitativa, que na perspectiva de Oliveira (2014) envolve a necessidade de definir um corte epistemológico, um tema central e os conceitos a serem investigados, sendo importante ressaltar a necessidade de uma análise descritiva.

Segundo Gerhardt e Silveira (2009) na abordagem qualitativa "o pesquisador é ao mesmo tempo sujeito e objeto de suas pesquisas" (p. 32), pois procuramos analisar o porquê dos acontecimentos observados, evidenciando características que necessitam ser constatadas com as ideias dos autores revisados, e um desenvolvimento envolvido por fatos repentinos, ressaltando a compreensão e explicação da dinâmica das relações sociais.

Nesta investigação, desenvolvemos ainda uma pesquisa bibliográfica, de acordo com Oliveira (2014), que considera necessário "analisar definições em textos, livros e documentos, em direção a uma visão sistêmica da temática em estudo" (p. 123). É possível também que se compreenda os conceitos utilizando a Metodologia Interativa, já que essa nova proposta metodológica está fundamentada "no novo paradigma da ciência contemporânea, que é o da visão sistêmica" (OLIVEIRA, 2014, p. 125).

Nesse aspecto, se compreende que o processo de conhecimento necessita ser dinâmico, sistêmico, considerando que tudo precisa estar interligado, “ou seja, as partes só podem ser entendidas a partir do todo" (OLIVEIRA, 2014, p. 125). Consideramos também que é importante essa leitura e organização do que já se conhece sobre determinados conceitos, pois somente desta maneira se torna possível afunilar as observações preliminares sobre o objeto de pesquisa, possibilitando melhor direcionamento para a observação do fenômeno em estudo.

O lócus dessa investigação foi o Clube de Ciências "Prof. Dr. Cristovam W. P. Diniz, da Universidade Federal do Pará - campus Castanhal, que por apresentar-se como um espaço não formal de ensino, procura trabalhar com problemas simples que envolvam atividades 
interdisciplinares, propondo intervenções pedagógicas que sejam capazes de levarem os alunos a discutirem e sugerirem soluções compatíveis ao seu desenvolvimento cognitivo e sua visão de mundo, podendo auxiliar ainda no desenvolvimento e manifestação de Habilidades Cognitivas em seus estudantes (MALHEIRO, 2016).

Além disso, este ambiente procura implementar um ambiente de educação não formal, proposto para o ensino, pesquisa e extensão de ações didáticas relacionadas a ciências e matemáticas (MALHEIRO, 2016).

A atividade que serviu de base para a realização dessa pesquisa foi intitulada "Problema do copo", e discutia a existência do ar e do espaço ocupado por ele. Durante cada atividade realizada, os estudantes perpassaram por etapas nas quais foram orientados a agirem e refletirem sobre o que estava sendo realizado.

Foram etapas que se superpuseram, porém, necessitaram de cautela dos professores monitores, para conseguirem auxiliar os alunos a realizarem as atividades e compreenderem a função de cada uma delas. Esses passos são divididos em sete momentos, nos quais as intervenções dos professores monitores são imprescindíveis para o sucesso dos mesmos (CARVALHO et al., 2009). São esses:

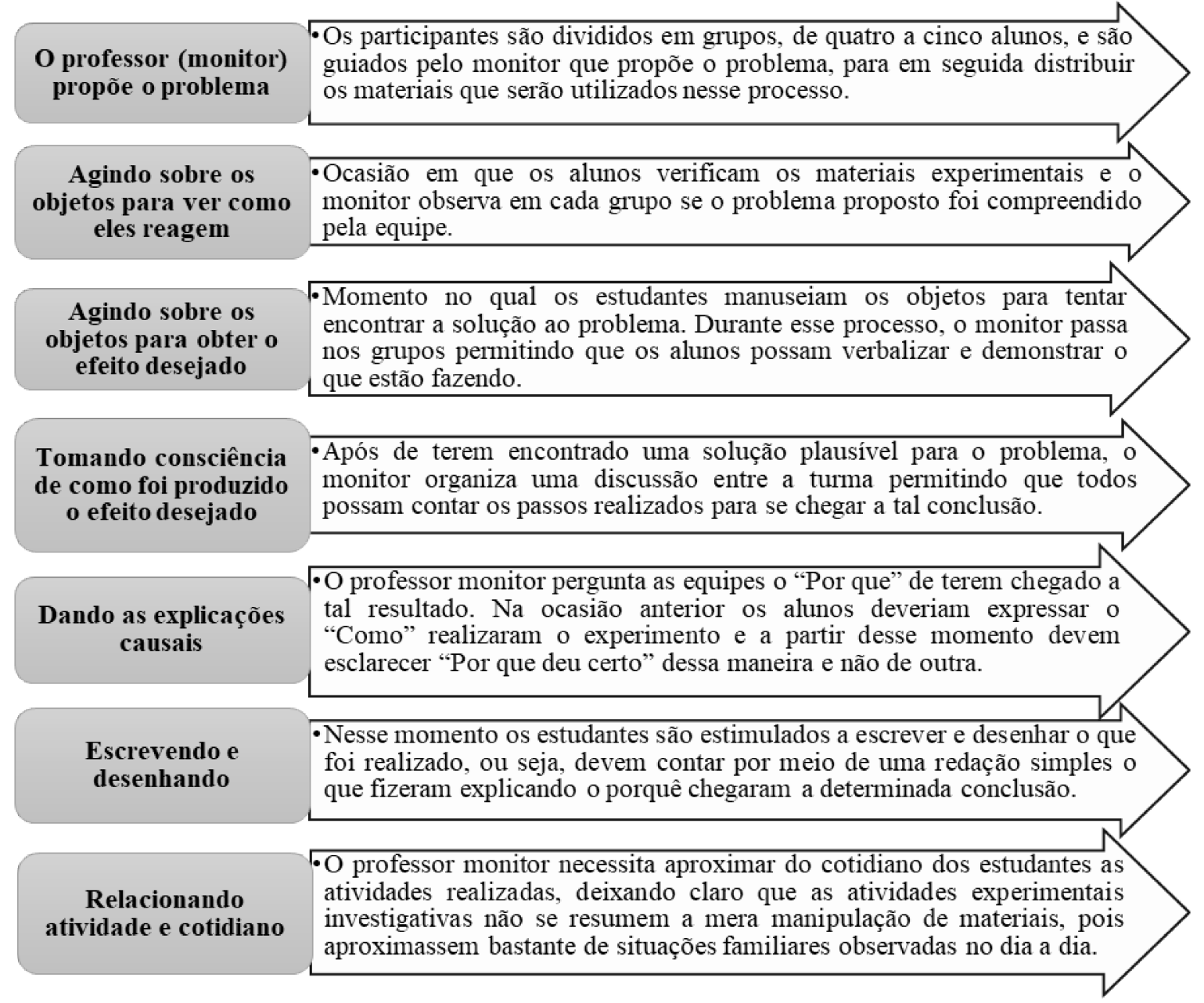

Figura 2: Sequência de Ensino Investigativo

Fonte: Adaptado de Carvalho et al. (2009) 
Estas etapas comumente são realizadas em dois sábados consecutivos, ou seja, a cada dois sábados conclui-se um ciclo de experimentação investigativa. Sendo assim, no primeiro sábado realizamos as seis primeiras etapas e, no segundo, a sétima que corresponde ao momento em que os estudantes já solucionaram a problemática inicial e, com apoio dos professores monitores, discutem os conceitos científicos que envolvem a temática abordada, almejando aproximá-la ao cotidiano dos alunos a partir da utilização de vídeos, dinâmicas, jogos, brincadeiras, apresentações de slides, dentre outros.

Contamos com a participação de 22 alunos entre 9 e 13 anos, estudantes do $5^{\circ}$ e $6^{\circ}$ anos do ensino fundamental, que foram distribuídos em grupos de 4 e 5 integrantes, sendo que cada um grupo contou com o auxílio de um professor monitor ${ }^{2}$. Dentre estes alunos, selecionamos uma equipe composta por 5 estudantes, para análise de suas falas e Interações. Para preservar a identidade dos sujeitos envolvidos, nomeamos os alunos de A1 a A5 e o professor monitor responsável pela equipe como Prof.

No decorrer da atividade, os alunos manipularam os materiais (papel toalha, copo, bacia com água), com o objetivo de responder a questão-problema: Como será que a gente faz para colocar este papel dentro do copo e afundar o copo na água, sem molhar o papel? Os estudantes fizeram várias tentativas para solucionar o problema, movimentando o copo de diversificadas maneiras e dobrando o papel em diferentes formados.

Depois de tentarem variadas formas, colocaram o papel dentro do copo e viraram de "boca" para baixo, empurrando desta forma na bacia com água, chegando a solução do problema. Desta maneira, os alunos descobriam que a água não conseguiu entrar no copo, porque nele existe ar e, dois corpos não podem ocupar o mesmo lugar ao mesmo tempo.

É importante frisar que, os professores monitores não deram respostas aos alunos, pois em cada uma das etapas desenvolvidas, foram os estudantes que organizaram, manipularam e definiram os passos que tomaram.

Aos professores monitores, coube a função de auxiliar, quando solicitado e quando consideraram pertinente, em ocasiões de dúvidas ou em momentos nos quais os alunos fizeram questionamentos sobre o que estavam observando. Sendo que, em vez de dar respostas, os professores monitores somente direcionaram e reformularam as perguntas dos alunos para conduzi-los, assim, a resolução do problema.

\footnotetext{
${ }^{2}$ Nome dado aos professores que acompanham os alunos na tarefa de resolverem os problemas, porém, sem dar a resposta, mas proporem outras questões que possam fazer os alunos refletirem sobre as decisões que precisam tomar para elucidarem a questão problema.
} 
As relações existentes entre as Interações Discursivas e as Habilidades Cognitivas em um

\section{Clube de Ciências}

Selecionamos para análise os momentos referentes ao segundo sábado de atividades, no qual utilizamos a sétima e última etapa da Sequência de Ensino Investigativo (CARVALHO et al., 2009), Aproximação com a realidade. Nesta ocasião os alunos já realizaram as seis primeiras etapas e, por isso, já começam a utilizar alguns termos científicos, que foram inseridos em seu vocabulário a partir das discussões iniciais na semana anterior.

Deste modo, a atividade iniciou com o Prof. solicitando aos alunos que pudessem comentar um pouco sobre o que havia sido realizado e demonstrassem aos colegas como tinham realizado o experimento, para obter uma solução plausível a problemática inicial.

Esse momento, de acordo com Carvalho et al. (2009) é muito importante, pois permite que os estudantes interajam e recordem o que fizeram ajudando-os a compreender melhor as discussões que serão propostas, por conseguinte.

Nesta ocasião, os estudantes revelaram estar empolgados e solícitos em evidenciar como o experimento ocorreu. Assim, dois alunos foram à frente do grupo e começaram a realizá-lo. No entanto, um dos alunos não conseguiu executar com presteza, pois ao amassar o papel, não o encaixou corretamente no fundo do copo.

Vendo esta ação, A1 verbalizou que isto aconteceu "porque ela não colocou direito dentro do copo... dobra o papel direito!". Assim, verificamos que A1 evidenciou Habilidades Cognitivas de nível N2, pois manifestou ser capaz de reconhecer a situação problemática, identificando o que precisou ser feito para resolvê-la, mesmo que ainda não justificasse sua resposta com base nos conceitos científicos que a contemplaram (ZOLLER et al., 2002).

Esse momento inicial teve continuação com a utilização de um segundo desafio proposto pelos professores monitores, com o objetivo de que os alunos conseguissem encher uma bexiga que estava presa a uma garrafa pet de 500ml. Neste desafio, os estudantes deveriam identificar o que havia de diferente entre as garrafas, pois em uma delas a bexiga poderia ser facilmente cheia de ar e a outra não permitia esse feito.

Assim, eles deveriam perceber que a garrafa na qual foi possível encher a bexiga havia um pequeno buraco feito com prego ao fundo, enquanto que a outra não possuía furos, observando que o ar ocupa lugar no espaço e, por isso, a garrafa furada permitia que o ar circulasse e a sem furos, impedia a entrada do ar na bexiga.

Observamos no quadro a seguir que, com precisão os alunos perceberam o que thes impediu de encher a bexiga, porém, ainda foi necessário ordenar melhor as informações obtidas com as atividades realizadas anteriormente para, em seguida, tornarem-se capazes de responder as perguntas feitas pelo professor monitor, conforme apresentamos a seguir: 
Quadro 2: Aproximação com a realidade

\begin{tabular}{|c|c|c|c|c|c|}
\hline \multirow{2}{*}{ Turno } & \multirow{2}{*}{ Discurso } & \multicolumn{4}{|c|}{ Análise dos dados } \\
\hline & & $\begin{array}{c}\text { Abordagem } \\
\text { Comunicativa }\end{array}$ & $\begin{array}{l}\text { Padrão de } \\
\text { Interação }\end{array}$ & $\begin{array}{l}\text { Intervenções } \\
\text { do Prof. }\end{array}$ & $\begin{array}{c}\text { Habilidades } \\
\text { Cognitivas }\end{array}$ \\
\hline 01 & $\begin{array}{l}\text { Prof.: Eu trouxe um desafio } \\
\text { para vocês... Quem é corajoso } \\
\text { aqui?? }\end{array}$ & \multirow{2}{*}{$\begin{array}{l}\text { Interação } \\
\text { Dialógica }\end{array}$} & & & \\
\hline 02 & ALUNOS: EU!!! & & & & \\
\hline 03 & $\begin{array}{l}\text { Prof.: Quem vai querer vir } \\
\text { aqui? (mostrando duas garrafas } \\
\text { pet de } 500 \mathrm{ml} \text {. Dois alunos se } \\
\text { dispuseram a participar) }\end{array}$ & \multirow{7}{*}{$\begin{array}{l}\text { Interativo de } \\
\text { autoridade }\end{array}$} & \multirow{3}{*}{$\begin{array}{l}\text { I - Interação } \\
\text { do professor }\end{array}$} & & \\
\hline 04 & $\begin{array}{l}\text { Prof.: Tenho duas garrafas, } \\
\text { vocês vão colocar os balões na } \\
\text { boca da garrafa, o desafio de } \\
\text { vocês é encher o balão dentro } \\
\text { da garrafa, ele (balão) tem que } \\
\text { estar dentro da garrafa (entrega } \\
\text { uma garrafa para cada aluno). }\end{array}$ & & & $\begin{array}{l}\text { Dando forma } \\
\text { aos } \\
\text { significados }\end{array}$ & \\
\hline 05 & Prof.: O que tá acontecendo? & & & $\begin{array}{l}\text { Checando o } \\
\text { entendimento }\end{array}$ & \\
\hline 06 & $\begin{array}{l}\text { A1: Não tá passando ar pra } \\
\text { bexiga, de repente... } \\
\text { (interrompido pelo A3). }\end{array}$ & & \multirow{3}{*}{$\begin{array}{c}\mathrm{R}- \\
\text { Resposta } \\
\text { dos alunos }\end{array}$} & & $\mathrm{N} 2$ \\
\hline 07 & $\begin{array}{l}\text { A3: Agora entendi, tava furada } \\
\text { embaixo. }\end{array}$ & & & & N4 \\
\hline 08 & $\begin{array}{l}\text { A1: É isso mesmo, a minha não } \\
\text { tá furada. }\end{array}$ & & & & N4 \\
\hline 09 & $\begin{array}{l}\text { Prof.: Descobriram! Com esse } \\
\text { desafio, nós queremos que você } \\
\text { relacione com o que nós } \\
\text { fizemos com o experimento... }\end{array}$ & & $\begin{array}{c}\text { A - } \\
\text { Avaliação } \\
\text { do professor }\end{array}$ & $\begin{array}{l}\text { Selecionando } \\
\text { significados }\end{array}$ & \\
\hline
\end{tabular}

Fonte: Produzido com base nos dados adquiridos com a pesquisa

Ao se considerar a capacidade humana de comunicação, percebemos que ela pode surgir por meio de palavras, gestos, expressões, e podem também ser identificadas cotidianamente nas mais diversas formas de Interações que ocorrem entre os sujeitos, conforme nos reporta Bakhtin (2006).

Nesse aspecto, em ambientes nos quais estas Interações costumam ser estimuladas, como ocorre no Clube de Ciências, percebemos que o discurso interativo entre alunos e professores monitores emergem em números bem maiores, pois observamos que os professores monitores estimulam sempre a participação dos estudantes, ou seja, são possíveis de verificar mais de uma voz, ocorrendo o que Mortimer e Scott (2002) nomeiam de interanimação de vozes.

Apesar de a abordagem comunicativa dialógica prevalecer, evidenciamos que em algumas ocasiões, o Prof. ofereceu a oportunidade de os alunos interagirem, utilizando o 
questionamento como forma de fazer com que surgissem opiniões, como ocorre nos turnos 01 e 02, por exemplo (AMARAL et al., 2003).

Com base nisso, percebemos que no turno 04, Prof. explica o desafio aos alunos intervindo com o intuito de dar forma aos significados, ou seja, procurou explorar o conhecimento prévio dos alunos (nesse caso seria a aproximação com o experimento trabalhado anteriormente), para a partir disso, trabalhar novos significados (MORTIMER; SCOTT, 2002).

Em sequência, no turno 05, Prof. se propõe a checar o entendimento dos estudantes verificando por meio de um questionamento simples, se eles estavam compreendendo a situação problema a que foram direcionados, verificando se havia consenso entre as equipes.

No decorrer da atividade, no turno 06, A1 manifestou Habilidade Cognitiva de nível N2 Logo, é possível inferir que A1 pode não ter concluído seu raciocínio por ter sido interrompido e, por isso, demonstrou reconhecer o problema proposto e o que deveria ter sido realizado para encontrar soluções a problemática, no entanto, ainda não identificava variáveis do problema e, com isso, sua resposta ficou inacabada, desconsiderando informações que poderiam ter sido relevantes para auxiliá-lo (ZOLLER et al., 2002; ZOLLER; PUSHKIN, 2007).

Por sua vez, A3 complementou a fala do colega encontrando a solução do problema "Agora entendi, tava furada embaixo". Percebemos que o aluno manifestou Habilidades Cognitivas de nível N4, pois este nível compreende o momento em que o estudante prontamente compreende as informações relevantes ao problema, suas variáveis e, portanto, se torna apto a elaborar sugestões de repostas mais consistentes aos objetivos da problemática (MATURANA, 2001; STERNBERG, 2010; COELHO, 2016).

Com o auxílio do colega, A1 conseguiu finalizar seu raciocínio, demonstrando também Habilidades Cognitivas de nível N4. Percebemos assim, a relação que se firma entre as Interações discursivas e a manifestação das Habilidades Cognitivas, pois a maneira como Prof. assumiu sua abordagem comunicativa influenciou diretamente nas respostas que foram dadas pelos alunos (SUART, 2008; COELHO, 2016).

Podemos perceber que mesmo com as repostas dadas pelos alunos, entre os turnos 03 a 09, Prof. evidenciou o discurso interativo de autoridade, já que ele não resgatou nenhuma das falas dos estudantes, esclarecendo somente que eles descobriram qual era a solução devida a questão proposta pelo desafio, e utilizando-se de perguntas para chegar a um ponto de vista específico, que era direcionar os alunos a aproximarem o desafio realizado com o experimento trabalhado anteriormente (MORTIMER; SCOTT, 2002).

Além disso, percebemos entre esses turnos o padrão de interação que é considerado o mais comum, dentro da perspectiva de Mortimer e Scott (2002), o I - R - A, que é um padrão 
demarcado pelas ocasiões em que o professor e os alunos alternam turnos de fala: Interação do professor (turnos 3, 4 e 5), Resposta dos alunos (turnos 6, 7 e 8), Avaliação do professor (turno 9).

Por fim, no turno 9 desse episódio, e ainda considerando a perspectiva dos autores, percebemos que Prof. fez uma seleção de significados, pois ele escolhe ignorar as falas anteriores, para priorizar o objetivo de sua proposta que era relacionar as duas atividades realizadas e os conceitos que as envolvia (AMARAL et al., 2003). O episódio a seguir iniciou a partir do questionamento de Prof. sobre "o que aconteceu com o copo e com a garrafa?", ao passo que os alunos responderam:

Quadro 3: Continuação da aproximação com a realidade

\begin{tabular}{|c|c|c|c|c|c|}
\hline \multirow{2}{*}{ Turno } & \multirow{2}{*}{ Discurso } & \multicolumn{4}{|c|}{ Análise dos dados } \\
\hline & & $\begin{array}{c}\text { Abordagem } \\
\text { Comunicativa }\end{array}$ & $\begin{array}{l}\text { Padrão de } \\
\text { Interação }\end{array}$ & $\begin{array}{c}\text { Intervenções } \\
\text { do Prof. }\end{array}$ & $\begin{array}{c}\text { Habilidades } \\
\text { Cognitivas }\end{array}$ \\
\hline 10 & $\begin{array}{l}\text { A2: O copo, o ar ficou preso } \\
\text { dentro do copo, aí essa } \\
\text { garrafa... o oxigênio... ele } \\
\text { também ficou preso aí, como } \\
\text { em nossos pulmões. }\end{array}$ & & $\begin{array}{c}\mathrm{P}- \\
\text { Prosseguime } \\
\text { nto da fala } \\
\text { do aluno }\end{array}$ & & N5 \\
\hline 11 & $\begin{array}{l}\text { Prof.: Vocês perceberam o ar } \\
\text { que fica saindo quando vocês } \\
\text { colocavam o copo com o } \\
\text { papel, porque sai aquelas } \\
\text { bolhinhas de ar de dentro, } \\
\text { mais ou menos assim oh: } \\
\text { aqui o ar fugindo (fazendo } \\
\text { movimento para cima com } \\
\text { uma das mãos representando } \\
\text { o oxigênio), quando o cara } \\
\text { tampa o nariz e fica lá } \\
\text { embaixo (referindo-se a } \\
\text { água) e começa a sair } \\
\text { aquelas bolinhas, é o ar do } \\
\text { pulmão. }\end{array}$ & \multirow{3}{*}{$\begin{array}{l}\text { Interativo } \\
\text { Dialógico }\end{array}$} & $\begin{array}{l}\mathrm{F}- \\
\text { Feedback do } \\
\text { Professor }\end{array}$ & $\begin{array}{l}\text { Revendo o } \\
\text { progresso }\end{array}$ & \\
\hline 12 & $\begin{array}{l}\text { Prof.: Vocês conseguem dar } \\
\text { um exemplo de que o ar } \\
\text { ocupa lugar no espaço? }\end{array}$ & & $\begin{array}{l}\text { I - Interação } \\
\text { do professor }\end{array}$ & $\begin{array}{l}\text { Marcando } \\
\text { significados } \\
\text { chaves }\end{array}$ & \\
\hline 13 & $\begin{array}{l}\text { A3: Com esse exemplo eu } \\
\text { consigo encher esse balão... } \\
\text { eu consigo encher ele sem, } \\
\text { sem... consigo fazer o efeito } \\
\text { da bomba dentro da água, } \\
\text { vou botar a água na bacia, aí } \\
\text { vou pegar a garrafa, aí vou } \\
\text { afundar a garrafa (descendo a } \\
\text { mão no sentido vertical), o } \\
\text { buraquinho que tem lá no } \\
\text { fundo vai puxar a água pra } \\
\text { dentro e aí vai encher a } \\
\text { garrafa e o ar vai sair. }\end{array}$ & & $\begin{array}{c}\mathrm{R} \text { - Resposta } \\
\text { do aluno }\end{array}$ & & N5 \\
\hline
\end{tabular}

Fonte: Produzido com base nos dados adquiridos com a pesquisa

Deste modo, no turno 10, A2 manifestou Habilidades Cognitivas de nível N5, já que o aluno demonstrou ser capaz de generalizar o conteúdo proposto inicialmente em outros 
contextos, isto é, não se limitou ao que estava sendo discutido, fazendo aproximações com temáticas que poderiam ter sido tratadas em outros ambientes (COELHO, 2016).

De acordo com Miri et al. (2007) é o momento de descoberta de uma teoria ou conceito já antes formulado, mas que neste momento pertence a um lugar que não se resume unicamente às teorias discutidas, é um saber prático que o próprio aluno constrói junto dos pares, com auxílio de alguém mais experiente.

No turno 11, Prof. revela o progresso, que os alunos obtiveram até este ponto, já que procurou recapitular os significados dos resultados, revendo progressos, aproximando os conceitos abordados a situações cotidianas, valorizando o discurso interativo/dialógico, por meio das ideias apresentadas pelos estudantes.

Em continuação a sua fala, Prof. acabou marcando significados chaves, ressaltando os conceitos estudados que, neste caso, são definidos por padrões de interação não-triádicas do tipo P - F - I - R, que remete a Prosseguimento da fala do aluno, seguido do Feedback do professor, que conclui sua fala por meio de uma Interação, e concluí o turno com a Resposta do aluno, de acordo com Mortimer e Scott (2002).

Como resposta a indagação proposta por Prof., no turno 13, A3 evidenciou características de Habilidades Cognitivas de nível N5, já que ele expôs por meio de um exemplo simples, baseado nos experimentos realizados, que o ar ocupa um lugar no espaço e só seria possível que entrasse água na garrafa, quando o ar saísse através do buraquinho que os alunos verificaram, abordando os conteúdos em diferentes contextos, conforme esclarecem Zoller e Pushkin (2007).

Isso pode ser percebido por meio do exemplo dado pelo aluno, ao explicar que ao empurrar a garrafa contra a água, na posição vertical, bolhinhas de ar podem ser liberadas, permitindo que a água ocupe esse espaço. Dessa maneira, fica bem claro para o estudante que a água e o ar não podem ocupar o mesmo lugar ao mesmo tempo, pois é preciso que um saia para o outro entrar, caracterizando a Habilidade Cognitiva de nível N5.

Dando continuidade as discussões, no episódio a seguir, conseguimos evidências da participação mais ativa dos estudantes, conforme observamos no quadro 4. 
Quadro 4: Participação dos alunos

\begin{tabular}{|c|c|c|c|c|c|}
\hline \multirow{2}{*}{ Turno } & \multirow{2}{*}{ Discurso } & \multicolumn{4}{|c|}{ Análise dos dados } \\
\hline & & $\begin{array}{c}\text { Abordagem } \\
\text { Comunicativa }\end{array}$ & $\begin{array}{l}\text { Padrão de } \\
\text { Interação }\end{array}$ & $\begin{array}{c}\text { Intervenções } \\
\text { do Prof. }\end{array}$ & $\begin{array}{c}\text { Habilidades } \\
\text { Cognitivas }\end{array}$ \\
\hline 14 & $\begin{array}{l}\text { Prof.: Certo, ótimo. Mas e } \\
\text { aqui no experimento da } \\
\text { garrafa pet, por que encheu o } \\
\text { balão? }\end{array}$ & \multirow{8}{*}{$\begin{array}{l}\text { Interativo } \\
\text { Dialógico }\end{array}$} & $\begin{array}{l}\text { I - Interação } \\
\text { do professor }\end{array}$ & $\begin{array}{l}\text { Revendo o } \\
\text { progresso }\end{array}$ & \\
\hline 15 & A1: Por causa do oxigênio. & & $\begin{array}{c}\mathrm{R} \text { - Resposta } \\
\text { do aluno }\end{array}$ & & N3 \\
\hline 16 & $\begin{array}{l}\text { Prof.: Mas o ar tava dentro } \\
\text { da água ou da garrafinha? } \\
\text { Eu não entendi. }\end{array}$ & & $\begin{array}{c}\text { A - } \\
\text { Avaliação } \\
\text { do professor }\end{array}$ & $\begin{array}{l}\text { Checando o } \\
\text { entendimento }\end{array}$ & \\
\hline 17 & $\begin{array}{l}\text { A2: Não, tava na garrafa, se } \\
\text { tivesse na água ele não tinha } \\
\text { funcionado. }\end{array}$ & & $\begin{array}{l}\mathrm{P}- \\
\text { Prosseguime } \\
\text { nto da fala } \\
\text { do aluno }\end{array}$ & & N4 \\
\hline 18 & $\begin{array}{l}\text { Prof.: Onde encontramos o } \\
\text { oxigênio? }\end{array}$ & & $\begin{array}{l}\text { I - Interação } \\
\text { do professor }\end{array}$ & $\begin{array}{l}\text { Checando o } \\
\text { entendimento }\end{array}$ & \\
\hline 19 & $\begin{array}{l}\text { A3: Pra fazer aquele balão } \\
\text { de ar quente subir precisa do } \\
\text { gás, fogo e ar... }\end{array}$ & & $\begin{array}{l}\mathrm{R}-\text { Resposta } \\
\text { do aluno }\end{array}$ & & N5 \\
\hline 20 & $\begin{array}{l}\text { Prof.: Muito bom. Mas aqui } \\
\text { tem oxigênio? }\end{array}$ & & $\begin{array}{c}\text { A - } \\
\text { Avaliação } \\
\text { do professor }\end{array}$ & $\begin{array}{l}\text { Checando o } \\
\text { entendimento }\end{array}$ & \\
\hline 21 & $\begin{array}{l}\text { A4: Com certeza, se não } \\
\text { tivesse nós tava tudo... } \\
\text { (começa a pegar em seu } \\
\text { pescoço e faz gestos } \\
\text { indicando morte). }\end{array}$ & & & & N5 \\
\hline
\end{tabular}

Fonte: Produzido com base nos dados adquiridos com a pesquisa

Em consonância com os ideais de Bakhtin (2006), de construção dos enunciados a partir do reconhecimento e interação do "eu" com o "outro", identificamos que no turno 14 por meio de uma abordagem comunicativa interativo/dialógico o Prof. procurou auxiliar os estudantes para que pudessem rever o progresso alcançado, almejando que eles recapitulassem dentro da atividade, como e por que obtiverem determinado resultado (MORTIMER; SCOTT, 2002; CARVALHO et al., 2009).

Observamos que ao responder à pergunta de Prof., A1 manifestou Habilidades Cognitivas de nível N3, pois foi possível perceber que ele identificou algumas variáveis dos dados observados com o experimento, mesmo que ainda não fosse possível abranger seus significados conceituais evidenciados por uma resposta mais elaborada (ZOLLER; PUSHKIN, 2007)

No diálogo que segue, percebemos que o Prof. continuou evidenciando em grande parte de suas falas abordagem comunicativa interativo/dialógico, já que identificamos as 
vozes de todos os sujeitos envolvidos e não somente a voz científica (MORTIMER; SCOTT, 2002; BAKHTIN, 2006; 2011).

Com esse tipo de interação ganhando destaque ao longo dos turnos, percebemos que o professor monitor conseguiu guiar as atividades permitindo que ocorra o trânsito de ideias, problematizações, considerando e exercitando distintas visões de ordem cotidiana ou embasada no conhecimento científico escolar.

Acompanhando este tipo de discurso, percebemos que em quase todos os questionamentos ou inferências realizadas, o Prof. propôs-se checar o entendimento dos estudantes, já que verificamos preocupações em tentar esclarecer, explicar melhor os resultados ou ainda verificar se todos os envolvidos na atividade chegaram a um consenso (MORTIMER; SCOTT, 2002; BAKHTIN, 2006).

Além disso, percebemos padrões de interação do tipo triádico, I - R - A, demarcando os momentos de troca de falas entre os alunos e o professor monitor, que por vezes permitiu que ocorresse interações entre os envolvidos com a atividade, não se limitando a expor suas próprias ideias, dando voz aos estudantes.

Em consequência a isto, evidenciamos que as Habilidades Cognitivas manifestadas pelos alunos cresceram gradativamente, iniciando em N3 e alcançado o maior nível descrito por Zoller e Pushkin (2007) e Coelho (2016), que é o nível N5. Desta forma, percebemos que as Interações Discursivas identificadas nesta atividade, contribuíram significativamente para que os alunos manifestassem Habilidades Cognitivas de variados níveis, de acordo com o tipo de proposta, as indagações efetivadas e a influência da relação aluno/aluno e aluno/professor monitor.

\section{Considerações finais}

Esta investigação teve como objetivo analisar em que termos as Interações Discursivas podem influenciar na manifestação de Habilidades Cognitivas. Nesse aspecto objetivamos investigar como esse processo pôde ser observado no Clube de Ciências "Prof. Dr. Cristovam W. P. Diniz" da Universidade Federal do Pará - campus Castanhal.

Com isso, evidenciamos que através das Interações Discursivas motivadas a partir da realização de atividades experimentais investigativas, estabelecem-se conectivos entre o conhecimento científico e a realidade de seus participantes, assim evidenciamos a possibilidade da identificação de Habilidades Cognitivas, em razão de que as atividades que permitam aos alunos a oportunidade de resolverem problemas, auxilia significativamente em seu desenvolvimento cognitivo, o que pode ser destacado por meio da ampliação de habilidades durante cada atividade realizada. 
O Clube de Ciências, por se tratar de um ambiente que almeja a utilização da experimentação investigativa como forma de aprender ciências e matemáticas, vem contribuindo com o desenvolvimento do conhecimento científico em seus participantes, o que pode ser identificado por meio das Interações Dialógicas potencializadas pelos professores monitores ao proporcionarem momentos favoráveis ao desenvolvimento e manifestação de Habilidades Cognitivas, durante tais Interações.

Com isso, ao serem organizados em grupos, os alunos tiveram a oportunidade de ouvir as respostas dos demais colegas, interagindo entre si e com o professor monitor responsável, para organizarem sua resposta final, esclarecendo a importância da consolidação da relação do "eu" com o "outro".

Outro ponto relevante se refere aos conceitos que serviram de base para a realização das atividades, pois os professores monitores selecionaram cautelosamente os conteúdos estudados, já que eles não são escolhidos apenas por nomear algo ou somente por caracterizar alguns agrupamentos de teorias, mas por representarem atributos que envolvem compreender com maior clareza as características de cada fenômeno ou objeto estudado.

Percebemos que no Clube de Ciências, em grande parte das Interações prevalece o discurso interativo/dialógico que puderam ser identificadas como favoráveis a elaboração adicional de ideias pelos alunos, para que pudessem organizar melhor seu entendimento sobre o conceito estudado.

Além disso, as discussões levantadas durante a última etapa da Sequência de Ensino Investigativo auxiliaram para a manifestação de Habilidades Cognitivas de Alta Ordem, caracterizadas pela evidência dos níveis N4 e N5, muito embora em algumas ocasiões tenham sido evidenciadas Habilidades Cognitivas de Baixa Ordem, nos níveis N2 e N3.

O Clube de Ciências, lócus dessa investigação também merece destaque, pois esse espaço não formal de educação se propõe, desde a sua inauguração em 2015, a popularizar conceitos científicos de forma que os estudantes possam participar de todo o processo de desenvolvimento das atividades, permitindo ainda que professores em formação tenham a oportunidade de vivenciar metodologias ativas.

Essa participação ativa dos alunos faz com que fujamos de métodos tradicionais de ensino, tornando o estudante o centro de todo o processo de construção de seus conhecimentos científicos, tornando o Clube de Ciências um ambiente de aprendizagens e compartilhamento de experiências por meio das Interações que são promovidas nesse espaço.

É válido ressaltar ainda que cada uma dessas Habilidades manifestadas estava de acordo com a abordagem comunicativa destacada pelo professor monitor. Assim, enfatizamos a relevância de investigações que se relacionem a essa temática. Por conta disso, assumimos que as Interações Discursivas percebidas em um Clube de Ciências podem auxiliar no 
desenvolvimento e manifestação de Habilidades Cognitivas em seus alunos, dependendo da maneira como ocorrem as abordagens comunicativas propostas nas falas e ações de professores monitores.

\section{Agradecimentos}

O presente trabalho foi realizado com apoio da Coordenação de Aperfeiçoamento de Pessoal de Nível Superior - Brasil (CAPES) - Código de Financiamento 001 e do PNPD.

Ao Grupo de Estudo, Pesquisa e Extensão FormAÇÃO de Professores de Ciências e ao Clube de Ciências "Prof. Dr. Cristovam W. P. Diniz" da Universidade Federal do Pará (Campus Castanhal).

\section{Referências}

AMARAL, E. M. R.; SCOTT, P. H.; MORTIMER, E. F. Analisando relações entre aspectos epistemológicos e discursivos na sala de aula de Química. In: II ENCONTRO INTERNACIONAL LINGUAGEM CULTURA E COGNIÇÃO: REFLEXÕES PARA O ENSINO, 2003, Belo Horizonte... Anais, Belo Horizonte 2003.

BAKHTIN, M. M. Estética da criação verbal. $6^{a}$ ed. São Paulo: Editora WMF Martins Fontes, 2011.

BAKHTIN, M. M. Marxismo e filosofia da linguagem. São Paulo: Hucitec, 2006.

CARVALHO, A. M. P.; VANNUCCHI, A. I.; BARROS, M. A.; GONÇALVES, M. E. R.; REY, R. C. Ciências no Ensino Fundamental: o conhecimento físico. São Paulo: Scipione, 2009.

COELHO, A. E. F. O desenvolvimento de Habilidades Cognitivas em um Curso de Férias: a construção do conhecimento científico de acordo com a Aprendizagem Baseada em Problemas. 101f. Dissertação de Mestrado - Universidade Federal do Pará. Programa de PósGraduação em Educação em Ciências e Matemáticas, Belém, 2016.

GERHARDT, T. E.; SILVEIRA, D. T.; Métodos da pesquisa. Porto Alegre: Editora da UFRGS, 2009.

GUERRA, L. B. O diálogo entre a Neurociência e a Educação: da euforia aos desafios e possibilidades. Revista Interlocução. v.4, n. 4, p. 3-12, 2011.

LIPMAN, M. O pensar na educação. Petrópolis: Vozes, 1995.

MALHEIRO, J. M. S. Atividades experimentais no ensino de ciências: limites e possibilidades. Actio: Docência em Ciência, v. 1, n. 1, p. 107-126, 2016.

MATURANA, R. H. Cognição, ciência e vida cotidiana (org. e tradução: Cristina Magro e Victor Paredes). Belo Horizonte: Ed. UFMG, 2001.

MIRI, B.; DAVID, B. C.; ZOLLER, U. Purposely Teaching for the Promotion of Higherorder Thinking Skills: A Case of Critical Thinking. Science Education. v. 2, n. 27, p. 353-369, 2007. 
MORTIMER, E. F.; P. SCOTT. Atividade Discursiva nas Salas de Aula de Ciências: Uma ferramenta sociocultural para analisar e planejar o ensino. Investigações no Ensino de Ciências., v.7, n. 3, p. 283-306, 2002.

NERY, G. L. Interações discursivas e a experimentação investigativa no Clube de Ciências Prof. Dr. Cristovam Wanderley Picanço Diniz. Belém, PA. 97 f. Dissertação de Mestrado Universidade Federal do Pará. Programa de Pós-Graduação em Educação em Ciências e Matemáticas, Belém, 2018.

OLIVEIRA, M. M. Como fazer pesquisa qualitativa. 6.ed. Petropólis, Rio de Janeiro: Vozes, 2014

SILVA, A. A. B. INTERAÇÕES DISCURSIVAS EM UM CURSO DE FÉRIAS: A constituição do conhecimento científico sob a perspectiva da Aprendizagem Baseada em Problemas. 89f. Dissertação de Mestrado - Universidade Federal do Pará. Programa de Pós-Graduação em Educação em Ciências e Matemáticas, Belém, 2015.

STERNBERG, R. J. Psicologia Cognitiva. 5. ed. São Paulo, SP: CENGAGE Learning, 2010.

ZOLLER, U.; DORI, Y.; LUBEZKY, A. Algorithmic and LOCS and HOCS (Chemistry) Exam Questions: Perfomance and Attitudes of College Students. International Journal of Science Education. v. 24, n. 2, p. 185-203, 2002.

ZOLLER, U.; PUSHKIN, D. Matching Higher-Order Cognitive Skills (HOCS) promotion goals with problem-based laboratory practice in a freshman organic chemistry course.

Chemistry Education Research and Practice, v. 8, n. 2, p. 153-171, 2007.

\section{SOBRE OS AUTORES}

ANTONIA EDIELE DE FREITAS COELHO. Licenciada Plena em Pedagogia pela Universidade Federal do Pará (UFPA). Mestre em Educação em Ciências e Matemáticas pela Universidade Federal do Pará (UFPA). Doutoranda do Programa de Pós-Graduação em Educação em Ciências e Matemáticas pela Universidade Federal do Pará (UFPA). Integrante do Grupo de estudo, pesquisa e extensão Formação de Professores de Ciências. Professora monitora do Clube de Ciências "Prof. Dr. Cristovam W. P. Diniz" da Universidade Federal do Pará (Campus Castanhal).

JOÃO MANOEL DA SILVA MALHEIRO. Licenciado Pleno em Ciências Biológicas pela Universidade Federal do Pará (UFPA). Especialista em Ensino de Ciências pela Universidade do Estado do Pará (UEPA). Mestre em Educação em Ciências e Matemáticas pela Universidade Federal do Pará (UFPA). Doutor em Educação para a Ciência pela Universidade Estadual Paulista (UNESP). Pós-doutor em Ciências da Educação pela Universidade do Porto. Pós-Doutor em Educação para a Ciência da Universidade Estadual Paulista (UNESP Campus Bauru). Docente Associado I da Universidade Federal do Pará. Coordenador do Grupo de Estudo, Pesquisa e Extensão FormAÇÃO de Professores de Ciências. Coordenador do Clube de Ciências "Prof. Dr. Cristovam W. P. Diniz" da Universidade Federal do Pará (Campus Castanhal).

Recebido: 18 de março de 2019.

Revisado: 12 de agosto de 2019.

Aceito: 10 de outubro de 2019. 